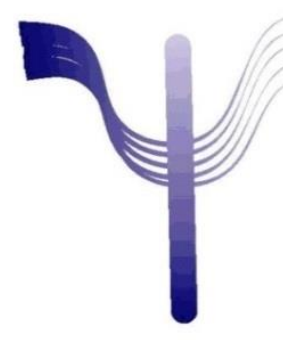

Maestría en Psicología de la Música Universidad Nacional de La Plata

Facultad de Bellas Artes.

\title{
Percepción musical en formato audio y audiovisual.
}

\section{Un estudio con jóvenes de $1^{\mathrm{er}}$ año de la Escuela Secundaria.}

\author{
Directora: \\ Dra. Silvia Raquel Malbrán \\ Maestrando: \\ Profesora Especialista Adriana María Piezzi \\ Diciembre 2016
}


A Silvia, querida maestra y guía en el camino musical, compañera de sueños y proyectos conjuntos, inspiradora en la tarea docente y en la investigación musical...

Estés donde estés, un GRACIAS inmenso e infinito...de corazón. 
Agradecimientos:

A Gustavo, mi marido, quien me alienta siempre a descubrir nuevos caminos y asumir nuevos riesgos.

A mis hijos, quienes me apoyaron en todo momento, desde el comienzo de este camino hasta el último ensayo de esta tesis.

A mi compañera docente, Alicia, quien me estimuló a finalizar este ciclo y me apoyó permanentemente.

A mis padres, a mis suegros y a mis hermanos Cristina, Laura, Gini, Eugenia, Gabriela y Gustavo, por el apoyo incondicional en $\mathrm{mi}$ trayecto humano y profesional.

A los alumnos de 10 año del Instituto Nuestra Señora de Pompeya, del Colegio Universitario Central “Don José de San Martín" de la UNCuyo y del Instituto Santa María Goretti (Luján de Cuyo). A sus directivos y preceptores quienes colaboraron en la implementación de la tesis y las pruebas realizadas.

GRACIAS 


\section{ÍNDICE}




\section{CAPÍTULO I}

\section{FUNDAMENTOS}

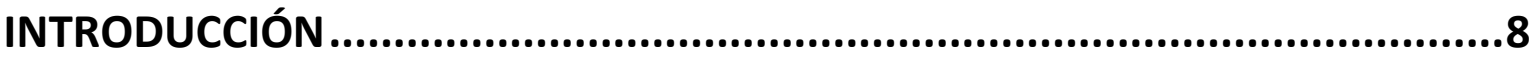

I.- MARCO TEÓRICO

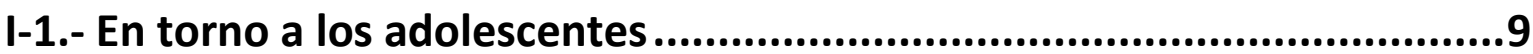

I-2. -La Cognición Musical: Modelos Psicológicos que la sustentan .............12

I-3.- El cruce de modalidades sensoriales..................................................13

I-4.- Justificación de la elección del Modelo Crossmodal.............................16

\section{CAPÍTULO II}

\section{METODOLOGÍA}

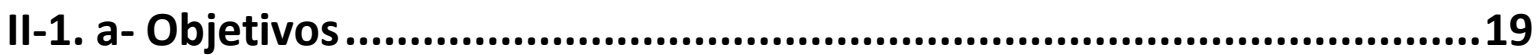

II-1. b -Supuesto Hipotético ......................................................................19

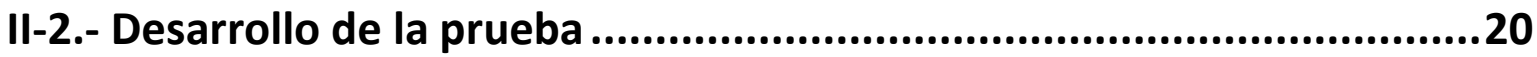

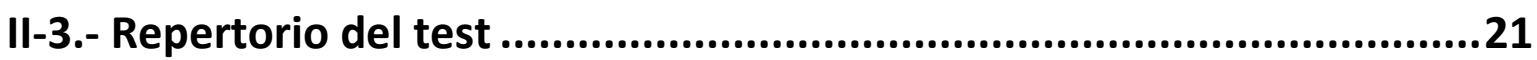

II-3. a -Criterios de selección de los fragmentos distractores .....................21

II-3. b- Criterios de selección de los textos verbales reforzadores ...............21

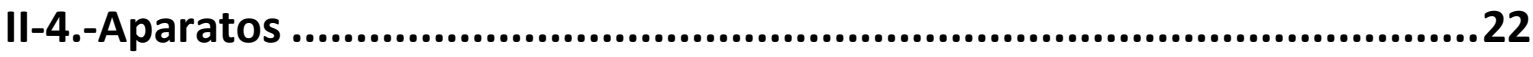

II-5.- Formulario de la prueba ..................................................................22

II-6.- Elaboración del estímulo experimental .............................................23

II. 7.- Aplicación del Test. Interacción tesista alumnos ...............................28

II.7. a- Guión para el grupo control ............................................................28 


\section{CAPÍTULO III}

\section{RESULTADOS}

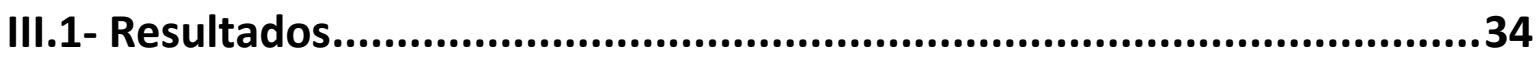

III.2-Administración y resultados de la Prueba piloto ...............................36

III.3- Conclusiones de la prueba piloto ......................................................39

III.4- Ajustes del experimento post prueba piloto.....................................39

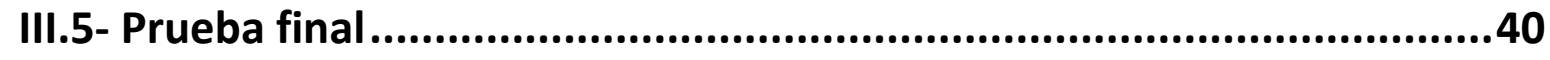

\section{CAPÍTULO IV}

\section{CONCLUSIONES Y APORTES POTENCIALES}

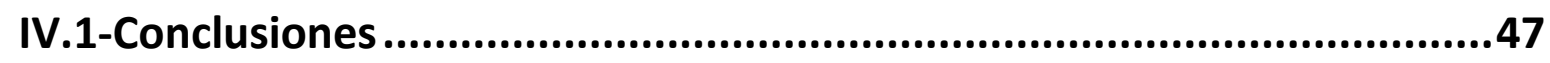

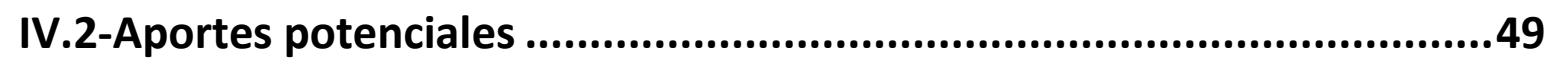

\section{CAPÍTULO V}

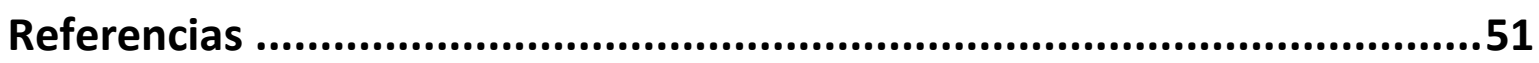

Bibliografía ..........................................................................................53 


\section{ANEXO}

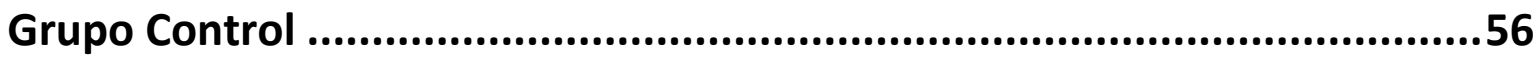

Grupo Experimental ....................................................................60 


\section{CAPÍTULO I.}

FUNDAMENTOS 


\section{INTRODUCCIÓN}

La educación musical en escuelas de nivel medio y particularmente en los primeros años del ciclo básico, muestra una brecha entre el universo de las prácticas estéticas juveniles y las provistas en las clases de arte.

La poderosa influencia de la cultura mediática ha generado un perceptor joven que encuentra placer al receptar multi-entradas sensoriales. El movimiento corporal, la danza, los efectos visuales, la música y la escena conforman un todo integrado y deslumbrante en los diversos productos de consumo por parte de los jóvenes.

Frente a ello la escuela les propone actividades que les demandan la puesta en juego de una estética por sobre las restantes: clases de música, de plástica, de teatro, en algunos casos... Los diversos currículos intentados en los últimos treinta años, no han derivado en cambios sustantivos de las modalidades de desarrollo artístico en la escuela. Las clases que mantienen al margen la cosmovisión de los jóvenes tarde o temprano provocan fatiga, pérdida de atención y falta de interés por los acontecimientos del aula.

La integración de disciplinas artísticas fue aplicada en diversos proyectos, sin embargo, no ha devenido en clases exitosas. La integración consistió fundamentalmente en encuentros de dos de las especialidades, las que compartían el ámbito físico, el tiempo de la clase y el contenido específico de cada dominio, de tal modo que si se trataba el tema forma en música se abordaba desde la estructura de la música, en expresión corporal desde la coreografía y en plástica desde lo pictórico o escultórico. La síntesis final y la transversalidad posible entre los enfoques es una cuestión que quedaba a 
cargo de los estudiantes. En tal sentido el modelo cross-modal se presenta como paradigma digno de ser tenido en cuenta. Sustenta que la correspondencia y congruencia entre los aspectos emocionales, temporales, sintácticos y argumentales de los discursos artísticos, resultan factores determinantes para la comprensión y degustación más acabada del arte. Dicha correspondencia y congruencia demanda una alineación estructural que pone en juego particularidades de cada uno de los lenguajes implicados.

La presente tesis aplica el modelo cross-modal para lo cual se ha construido un test relativo a la experiencia con un film que dramatiza el primer movimiento de la $5^{\text {ta }}$ Sinfonía de Beethoven (https://www.youtube.com/watch?v=EEhF-7suDsM), aplicación realizada en un contexto de escolaridad de nivel básico en escuelas mendocinas.

\section{I- MARCO TEÓRICO.}

\section{I-1 En torno a los adolescentes}

La complejidad del momento histórico con sus transformaciones económicas y tecnológicas conforma el ideario de un "mundo nuevo" (Rascovan, 2005). Una de las revoluciones más significativas es la tecnológica, la cual signa sus efectos en las diferentes actividades humanas.

En el mundo globalizado los adolescentes y jóvenes conviven con mundos virtuales caracterizado por la velocidad de la información, la invasión de imágenes a ritmo vertiginoso como en los video clips, la interactividad con los juegos electrónicos y la televisión, entre otros bienes culturales (Cano et al., 2011). 
Los jóvenes, construyen su identidad copiando el vestuario, el peinado, el lenguaje de sus ídolos. Son apropiaciones de objetos emblemáticos que los convierten en sujetos culturales, necesitados de acordar con otros en la manera que tienen de entender el mundo, de vivirlo, de identificarse y diferenciarse de otras generaciones.

Estos arquetipos generan conductas que comparten, sostienen y alimentan el deseo de ser independientes de la familia, a la que sustituyen con la dependencia a un grupo de pares. Allí se entramarán los significados sociales de los bienes culturales que consumen (Malbrán, M del C., 1992).

El entorno mass media los identifica y cohesiona, les sugiere patrones de conducta, códigos, formas de aprendizaje y lenguaje, artefactos culturales que se arraigan en los objetos que consumen, lo que configura un ideario y un sistema de creencias al que adhieren los miembros del grupo. Un elemento importante de cohesión, es la música. Este conjunto de comportamientos construye la identidad del grupo de pertenencia (Morduchowicz, 2004).

Para los adolescentes, la música es una forma de acompañamiento de la vida cotidiana, de sus reuniones sociales, fiestas y viajes. Es una forma de pertenecer, de comunicarse, de sentirse apropiadores de una estética que es tema de conversación y disfrute entre ellos. La pregunta crucial para los educadores es si en estas formas de apropiación estética pueden tener cabida otros estímulos musicales aparentemente no compatibles ni equiparables en grado de exposición, con los por ellos consumidos (De Nora, 2000; Hargreaves et al (2002).

El adolescente experimenta cambios puberales que guardan relación directa con sus transformaciones cognitivas, afectivas y sociales. Las relaciones entre el desarrollo físico y las adaptaciones están determinadas por el grado de aceptación y conciencia que tienen sobre cambios que se producen en esta 
etapa de su desarrollo. Es preciso atender a las influencias psicológicas y sociales que tienen dichos cambios en los adolescentes, las que se deben tener en cuenta a la hora de planificar una estrategia educativa (Malbrán, M del C., 1992).

Las transformaciones físicas $y$, por ende, sociales y afectivas, son variables, diversas y no suceden todas al mismo tiempo. Se producen por espacios de tiempo diferentes en función de las influencias ambientales y del entorno de cada adolescente en particular. Estas transformaciones tienen especial significación para los docentes, para los padres, para los grupos de pertenencia y para la sociedad en sí. El entorno en que se desarrollan los adolescentes influye en la maduración en el pensamiento y en el razonamiento, en la apropiación de principios morales y en el desarrollo de relaciones afectivas y sociales basadas en modelos constituidos desde la vivencia de experiencias personales de sociabilización y pertenencia con sus grupos (Malbrán, M. del C., 1992).

Los puntos de referencia que toman los adolescentes, como los centros comerciales, la televisión, las revistas, los recitales, redes sociales, son elementos clave para acceder a bienes culturales de los cuales escogen símbolos y signos con los que construyen sus identidades. Esta es la importancia que tiene el ambiente para promover formas más maduras de afecto, juicio moral y razonamiento (Morduchowicz, 2004).

Tender puentes entre los contenidos curriculares y el universo real en el que se mueven los jóvenes, entre la cultura letrada y la oral y audiovisual, en suma, entre la escuela y la cultura popular, es sin duda un emprendimiento desafiante.

El joven aprende con todos los sentidos y de todos los recursos externos de aprendizaje. Si está interesado aprovecha el entorno para desarrollar 
capacidades, habilidades, competencias de diversa factura. Es por ello que se parte de la premisa de que aprende a partir de diferentes modalidades de información. Esto le permite utilizar el conocimiento para comprender y transformar constructivamente su entorno social, ambiental, económico y cultural, situándose como participante activo en un mundo en permanente cambio (Malbrán, M. del C, 1992).

Es sustento de este trabajo

- "La ampliación de fronteras entre las disciplinas artísticas y los lenguajes tradicionales del arte y su sincretismo en la configuración de nuevas poéticas artísticas" (CFE. Resol. $\mathrm{N}^{\circ}$ $120 / 10, p: 9)$

- "La forma en que se accede, circula y se consume el arte en sus múltiples manifestaciones, desde el aporte de las nuevas tecnologías de la información y la comunicación, dando paso a los medios audiovisuales y multimediales". (DC de la UNCuyo, p: 23, 2012)

- La convivencia de lo global y local, lo tradicional y lo multimedial, lo textual e hipertextual, lo individual y lo colectivo, lo real y lo virtual como expresiones de diversidad cultural en el adolescente (CFE. Resol. N 120/10).

Se asume que la mayoría de las representaciones de índole artística y cultural con las que convivimos son ejemplos de integración de lenguajes que se encuentran vivos y vigentes en la calle, en los medios y en la conducta espontánea de los jóvenes. Se buscan modelos que permitan enseñar a aprender y a apreciar el valor de lo aprendido, esto es, modelos para aplicar estrategias nuevas desde caminos de apertura y en relación con los avances de la neurociencia, asuntos que constituyen un desafío para quienes se 
comprometen con la preparación de los jóvenes. Pensar en modos de comunicación más adecuada, flexibilizar esquemas que favorezcan los procesos mentales, escuchar los interrogantes planteados por los adolescentes para avanzar hacia el trabajo cooperativo en la búsqueda de respuestas y estrategias para desarrollar una formación desde todos los aspectos de desarrollo que involucran al sujeto de aprendizaje serían, probablemente, algunos de los caminos (Malbrán, M. del C., 1992).

"La valoración de la juventud que se hace en las sociedades occidentales y la esperanza que se deposita en la reserva que constituyen los jóvenes es un signo de esta época" (Malbrán, M. del C; 1992, p: 8).

\section{I-2 La Cognición Musical: Modelos Psicológicos que la sustentan.}

La música como artefacto cultural transmitido de generación en generación pone en juego procesos sensoriales, cognitivos, emocionales y motores. Se trata de la construcción, generalmente de manera inconsciente, de patrones y estructuras emergentes de las prácticas musicales heredadas. El producto de esta construcción es una representación musical que da cuenta del contexto artístico-social y funciona como generador multidimensional del pensamiento (Hemsy de Gainza, 2003).

La música es un arte auditivo conformado por relaciones sonoras que configuran estructuras, más que simples sucesiones de sonidos. Al acceder a estas estructuras, la música resulta significativamente más comprensible a las personas de la comunidad occidental. Esto se realiza mediante un proceso de percepción a partir del cual "utilizamos la información provista por nuestros sentidos para armar representaciones mentales del mundo que nos rodea" (Basso, 2009: p: 215). 
En 1983, F. Lerdahl (músico) y J. Jackendoff (lingüista) plantearon un modelo basado en la Psicología de la Gestalt y la Gramática Generativa de Noam Chomsky. En él proponen el análisis del discurso musical desde el agrupamiento de ideas que permiten el acceso a los datos musicales, en relación con la importancia de los componentes.

Estudios previos (Dowling 1994) obtuvo evidencia acerca del rol del contorno melódico entendido como el perfil "macro" del boceto de una melodía. Estas investigaciones y posteriores aportes revelaron el papel del contorno en aspectos tales como: la ontogénesis del canto infantil, la conservación de melodías no conocidas y la percepción de melodías atonales.

Avances en la Psicología (Bruner, 1997) y particularmente en la Psicología Cognitiva de la Música (Levitin, 1999) señalan que la información perceptiva se facilita e incrementa en su comprensión cuando se presenta, en forma concurrente, con la entrada de información por diferentes vías sensoriales (auditiva, visual, kinestésica). En tal sentido las producciones artísticas a las que se accede por vías sensoriales diferentes resultan facilitadoras para la comprensión, emoción y degustación de los receptores.

Los modelos de la Psicología de la Música que analizan el discurso musical en términos de agrupamiento sintáctico, contorno, alineamiento de los acentos temporales y saliencia tímbrica, resultan valiosos indicadores a la hora de diseñar estrategias metodológicas para la enseñanza.

\section{I-3.- El cruce de modalidades sensoriales.}

El modelo Cross-modal parte del principio de que las experiencias multisensoriales incrementan la comprensión y placer del auditor-espectador. 
Diversos Investigadores Cohen (2005), Reybrouck (2005), Lipscomb (1998) fundamentan dicho modelo en una estructura que permite una asignación interesante y flexible de la información.

En este modelo, la congruencia es entendida como alineamiento entre las sintaxis de las diferentes artes; "interesa en particular el alineamiento temporal entre música y escena" (Malbrán-Menéndez, 2009:2).

En estudios de Rollins, $(2005)^{1}$ se observó que las neuronas polisensoriales aumentan su actividad al exponerlas a experiencias multimodales y funcionan como intermediarias entre sistemas sensoriales.

Asimismo Stein y Meredith (1993) comprobaron "la presencia de neuronas multi-sensoriales en diversas áreas cerebrales, las cuales convergen dentro y a través de información multimodal". Por lo expuesto, se produce una gran transformación al integrar y "resetear" los datos sensoriales.

Los fundamentos biológicos del modelo se apoyan en los avances de la neurocognición y analizan el incremento de la actividad neuronal cuando la entrada es multisensorial ya sea que se parta de estímulos reales o virtuales. Los fundamentos psicológicos permiten recuperar procesos mentales subyacentes entre funciones cognitivas y brindan soporte a los juicios interpretativos, favoreciendo la eficacia comunicacional, la emoción y las asociaciones entre percepciones y datos temporales, entre otras (Cohen, 2001).

Las formas de conjunción entre las diferentes disciplinas expresivas desarrollan, en la mente del perceptor, mecanismos multimodales de integración que son el resultado de la congruencia en el cruce entre diferentes modalidades sensoriales. Estos mecanismos, demandan diferentes modos de interacción sensitiva que se apoyan en la preponderancia de un sentido sobre otros. Cuando esto ocurre, "tal predominio fluye entre una forma de arte y

\footnotetext{
${ }^{1}$ Citado por Malbrán, S. (2010)
} 
otra, reforzándose mutuamente en los diferentes puntos de conjunción" (...) a los que se les adjudica gran influencia en la percepción integral" (Malbrán, S. y Menéndez, J. 2009; p:3).

Las expresiones artísticas como la danza en relación con la música o la música con el film, se integran en una nueva fusión al obtener un arreglo eficaz en el tiempo y, es por ello, que son considerados "discursos multimodales". Diversos estudios previos, muestran que existen componentes biológicos y psicológicos que fundamentan la importancia del Modelo Cross-modal.

En un trabajo de Fogelsanger y Afanador -coreógrafo y compositor (2006) se analizaron aspectos de la integración entre dos lenguajes artísticos: la música y la danza. Los resultados de dichos estudios revelaron que la condición relevante es la congruencia. Esto se entiende desde el ajuste entre el desarrollo de los eventos musicales y los coreográficos. Los autores elaboraron un listado de aspectos que operan paralelamente entre el pulso y el ritmo de la música y aspectos estructurales del movimiento.

La coordinación de estímulos sensoriales receptados por diferentes vías sensoriales son considerados mecanismos multimodales de integración de mayor eficacia cuando logran congruencia de modalidad cruzada (Malbrán, S.; 2010).

Percibimos lo que nos rodea a través de los sentidos. La información que obtenemos de nuestro entorno proviene de fuentes auditivas, motoras, olfativas, visuales. Autores como Stein y Meredith (1993) y Deneve y Pouget $(2004)^{2}$ consideran que dicha percepción, más que una serie de experiencias sensoriales independientes, es incorporada "como un interjuego de impresiones distintas a través de las cuales los componentes sensoriales son

\footnotetext{
${ }^{2}$ Citado por Malbrán y Menéndez, (2009)
} 
sutilmente alterados por una integración mutua" (Malbrán y Menéndez, 2009; $\mathrm{p}: 2)$.

La cross-modalidad atiende a la congruencia entre lenguajes artísticos a partir del alineamiento de acentos temporales y la correspondencia en la saliencia perceptiva de la música, el contorno melódico, los efectos tímbricos y el significado emocional (Malbrán, S.; 2010).

Las distintas expresiones artísticas, muestran puntos de conjunción entre los acentos y pautas que transcurren en el tiempo; se producen así "lazos de conexión cross-modal" (Malbrán, S.; 2009). Dos realizaciones son congruentes cuando puntos de cada discurso coinciden en el tiempo. Por otro lado, el cruzamiento remite a la cooperación neuronal producida por la entrada de estímulos multimodales. Se ha mostrado, a partir de la Psicología Cognitiva, que el cerebro, involuntariamente, reconoce lazos conectivos esenciales para favorecer procesos de percepción integral. Estos son fundantes para el desarrollo de mecanismos de atención selectiva y para poder "comprometer sinergias espaciales en el procesamiento atencional de información cruzada entre modalidades sensoriales" ${ }^{3}$ (Wood, 1998).

\section{I-4 Justificación de la elección del Modelo Cross-modal}

Sumariamente

- Los avances de la tecnología permiten sintetizar imágenes y sonidos simultáneamente en tiempo real, generando productos integrados entre varias modalidades audiovisuales (Hunt et. al 1998). Las formas de conjunción son

\footnotetext{
${ }^{3}$ Citado por Malbrán, (2010)

${ }^{4}$ Citado por Cádiz y De la Cuadra
} 
mecanismos multimodales de integración que son más eficaces al lograr congruencia de modalidad cruzada. Estas formas dan cuenta de diferentes modos de interacción sensitiva al basarse en el predominio de los sentidos. Las distintas formas del arte se refuerzan entre sí buscando los puntos de conjunción y lazos de conexión a los que se les asigna una gran influencia en la percepción integral. (Malbrán y Menéndez, 2009).

- La información disponible sobre el cerebro humano se ha visto incrementada debido al desarrollo de las nuevas técnicas de visualización cerebral. Como consecuencia de estas investigaciones recientes, aparece una nueva disciplina en la que confluyen los conocimientos generados por la Neurociencia, la Educación y la Psicología, los que pueden aportar información significativa sobre el proceso de enseñanza y aprendizaje. La neuro-educación aprovecha los conocimientos sobre el funcionamiento cerebral para enseñar y aprender mejor.

- La mente recibe información por diferentes vías sensoriales integrando, de este modo, las vías de entrada en un nuevo complejo perceptual. Éste se enriquece notoriamente desde la percepción de los estímulos en forma conjunta más que separada. La actividad neuronal se ve afectada por la estimulación multisensorial y, a partir de la acción simultánea de diferentes centros cerebrales, se produce como resultado una nueva conjunción, enriquecida por múltiples entradas sensoriales (Cohen, 2005; Fogelsanger y Afanador, 2006) $)^{5}$.

- El cerebro humano es extraordinariamente plástico, puede adaptar su actividad y cambiar su estructura de forma significativa a lo largo de la vida. Todo lo que se vive, desde la experiencia, modifica nuestro cerebro fortaleciendo o debilitando las sinapsis que conectan las neuronas, generando

\footnotetext{
${ }^{5}$ Citado por Malbrán, (2010)
} 
así el aprendizaje que es favorecido por el proceso de regeneración neuronal llamado neurogénesis. Esta plasticidad cerebral resulta fundamental desde la mirada educativa ya que puede posibilitar en los alumnos el aprendizaje efectivo (Guillén, 2012).

- Los aspectos que han modificado la mirada de la educación musical actual son aquellos que presentan un carácter más sensorial y directo, aquellos que surgen al profundizar en el sonido, o sea en el "polo material" de la música (Hemsy de Gainza, 2002). 


\section{CAPÍTULO II}

\section{METODOLOGÍA}




\section{II-1 a Objetivos}

- Construir un test a suministrar a dos grupos naturales de 1er año básico divididos aleatoriamente en grupo control y grupo experimental.

- Elegir 10 fragmentos musicales de L. Van Beethoven en idéntica tonalidad, con similitud tímbrica, cinco de ellos originales y cinco distractores provenientes de otras obras del autor.

- Realizar una prueba piloto en otro establecimiento educativo con un grupo de conformación socioeconómica similar y también perteneciente al ciclo básico.

- Ajustar la prueba experimental de acuerdo con los resultados de la prueba piloto.

- Suministrar la prueba al total de la muestra en igual día y sin contacto entre el grupo saliente y el grupo entrante al experimento.

- Seleccionar las pruebas estadísticas apropiadas para analizar la data.

- Analizar los resultados obtenidos en los grupos de control y experimental en términos cuantitativos y cualitativos.

\section{II-1 .b Supuesto Hipotético}

Alumnos de $1^{\text {er }}$ año de nivel medio, de similar condición socioeconómica, e idéntico nivel de escolaridad y número de exposiciones a la obra, obtendrán diferentes resultados al reconocer fragmentos de una Sinfonía 
clásica según accedan a la obra en formato solo audio o en formato multisensorial (audio, visual y verbal).

\section{II-2 Desarrollo del tratamiento}

Los alumnos del grupo control cumplieron las siguientes acciones

a) Escucharon (en versión solo audio) el $1^{\text {er }}$ movimiento de la $5^{\text {ta }}$ Sinfonía.

b) Escucharon los cuatro fragmentos seleccionados de la obra, con alusiones a la tímbrica y carácter de los mismos.

c) Escucharon nuevamente el $1^{\text {er }}$ movimiento completo de la $5^{\text {ta }}$ Sinfonía.

d) Cumplimentaron el test en el cual fueron presentados ocho fragmentos instrumentales de Beethoven: cuatro originales, pertenecientes a la obra escuchada y cuatro distractores, pertenecientes a otras obras del mismo autor. Los fragmentos se distribuyeron aleatoriamente. Los estudiantes contestaron un cuestionario en el que determinaron cuáles de los fragmentos pertenecen a la $5^{\text {ta }}$ Sinfonía y cuáles no. Al momento del test no se les especificó cuántos pertenecían a una u otra categoría.

Los alumnos del grupo experimental cumplieron las siguientes acciones

a) Participaron como espectadores del film completo "Argumento para la $5^{\text {ta }}$ Sinfonía ( $1^{\mathrm{er}}$ movimiento)

b) Vieron como espectadores los cuatro fragmentos seleccionados con alusiones a la tímbrica y carácter de los mismos comentarios ampliados por frases verbales alusivas a la trama del film.

c) Participaron nuevamente como espectadores del film completo

e) Cumplimentaron el test (idéntico al del grupo control) en el cual se presentaron ocho fragmentos instrumentales de Beethoven: cuatro 
originales, pertenecientes a la obra escuchada y cuatro distractores, pertenecientes a otras obras del mismo autor. Los fragmentos fueron distribuidos aleatoriamente. Los estudiantes contestaron un cuestionario en el que determinaron cuáles de los fragmentos pertenecían a la $5^{\text {ta }}$ Sinfonía y cuáles no. Al momento del test no se les especificó cuántos pertenecían a una u otra categoría.

\section{II-3 Repertorio del test}

Los ejemplos musicales seleccionados fueron 8 fragmentos de Beethoven. Cuatro pertenecientes a la $5^{\text {ta }}$ Sinfonía (originales) y cuatro pertenecientes a otras obras de Beethoven (distractores).

\section{Fragmentos distractores}

Fragmento A 2. Beethoven Sinfonía 3: $3^{\mathrm{er}}$ movimiento. Comienzo del trío Fragmento C 2. Beethoven Sinfonía 3; $3^{\text {er }}$ movimiento Fragmento D 2. Beethoven Sinfonía 3; $3^{\text {er }}$ movimiento Fragmento B2. Beethoven Trío para 2 oboes y corno inglés sobre un tema de “Don Juan" de Mozart Las prácticas y el test se desarrollaron el mismo día, sin que los estudiantes del grupo control interactuaran con los estudiantes del grupo experimental en los momentos de cambio de un grupo a otro para la prueba.

El trabajo se realizó en el local escolar, en el aula de clase. 


\section{II-3 a Criterios de selección de los fragmentos distractores}

i) Similar extensión en número de tactus

ii) Igual o similar arreglo tímbrico

iii) Igual tono-modalidad o predominio de alturas comunes

iv) Congruencia entre palabra, carácter de la música y gesto corporal

\section{I-3 b Criterios de selección de los textos verbales reforzadores}

i) Similar distribución entre la palabra y la rítmica del fragmento

ii) Coincidencia entre el carácter musical y el gesto corporal de los actores

iii) Mímica que remeda el uso que se hace de esos gestos en la vida cotidiana

\section{II-4 Aparatos}

1. Equipo para la proyección del film: Epson-Modelo EMP-S1H-

Equipo de audio con amplificador: modelo NoAZ 1839/77-PHILIPS 
II-5 Formulario de la prueba

\section{Cuestionario final}

GRUPO ......... Sexo.

Nombre o seudónimo (optativo)

A continuación escucharás ocho fragmentos musicales.

Algunos de ellos pertenecen a la $5^{\text {ta }}$ Sinfonía de Beethoven y otros no.

Marca con cruz tu respuesta PARA CADA FRAGMENTO.

\begin{tabular}{|l|l||l|}
\hline & SI & NO \\
\hline \hline Fragmento 1 & & \\
\hline \hline Fragmento 2 & & \\
\hline \hline Fragmento 3 & & \\
\hline \hline Fragmento 4 & & \\
\hline \hline Fragmento 5 & & \\
\hline \hline Fragmento 6 & & \\
\hline \hline Fragmento 7 & & \\
\hline \hline Fragmento 8 & & \\
\hline
\end{tabular}

Gracias por tu colaboración! 


\section{II-6 Elaboración del estímulo experimental}

\section{Tema A 1.}

- Original - $5^{\text {ta }}$ Sinfonía $1^{\text {er }}$ movimiento

Tímbrica: Sólo de Corno

Métrica: Compás 59 a 64

Minutaje de la filmación: 3.40.a.3.42

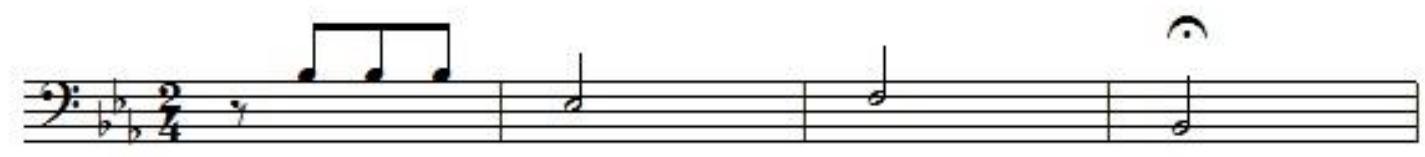

Texto: Vamos a ver A ver

Congruencia rítmico /acentual y carácter (gesto/música)

\section{Tema A 2.}

- Distractor-Beethoven $3^{\text {ra }}$ Sinfonía $2^{\text {do }}$ Movimiento

Comienzo del trío

Tímbrica: Corno

Métrica: Anacrusa compás 166 a 173. Página: 302

Minutaje de la versión audio: 2.45 a 2.50

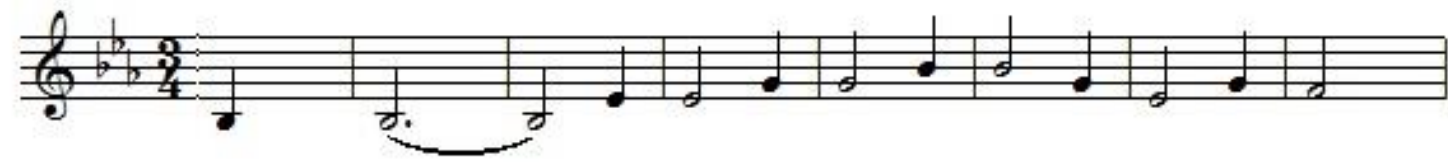




\section{Tema B 1.}

- Original - $5^{\text {ta }}$ Sinfonía $1^{\mathrm{er}}$ movimiento

Tímbrica: Sólo de Oboe

Métrica: Compás 268

Minutaje de la filmación: 3.10 a 3.49

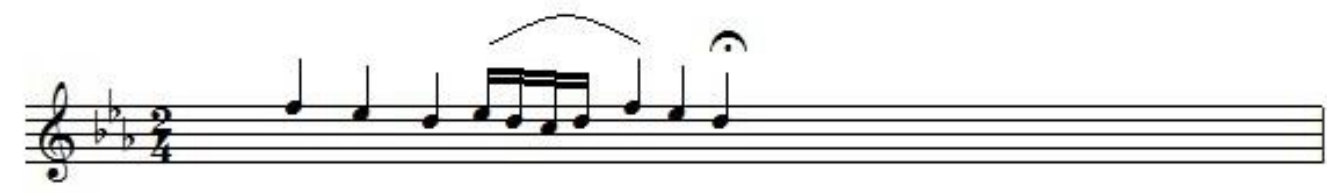

Texto: Estoy sufriendo mucho

Congruencia entre carácter (música /gesto) y rítmica libre con rubato

\section{Tema B 2.}

- Distractor -Beethoven. Trío para 2 oboes y corno inglés sobre un tema de "Don Juan" de Mozart.

Tímbrica: Oboe

Minutaje de la versión audio: 3.15 a 3.20
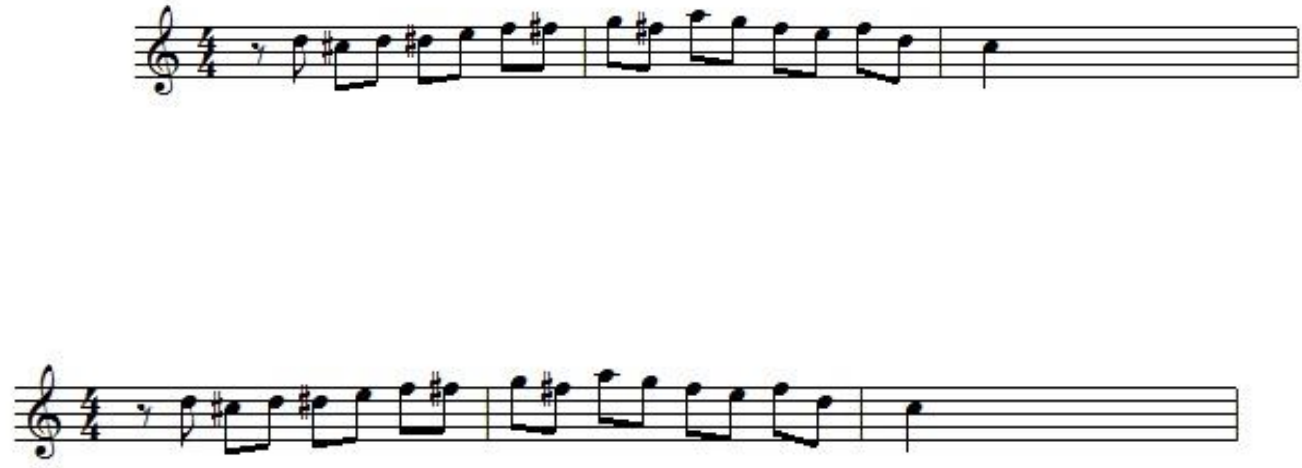


\section{Tema C 1.}

- Original - Beethoven. $5^{\text {ta }}$ Sinfonía $1^{\text {er }}$ movimiento

Tímbrica: Alternancia cuerdas y maderas

Métrica: Compás 63 a 70

Minutaje de la filmación: 3.47 a 3.52

Clarinete violines

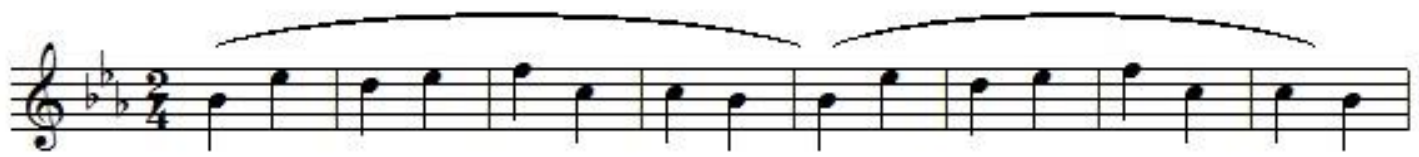

Texto: Yo seré muy razonable Yo seré muy razonable. Congruencia entre carácter (gesto /música) y procedimiento compositivo (repetición exacta)

\section{Tema C 2.}

- Distractor-Beethoven. $3^{\text {ra }}$ Sinfonía $1^{\text {er }}$ movimiento

Tímbrica: Alternancia entre violines, oboe/fagot y violines

Métrica: Compás 154 a 160

Minutaje de la versión audio: 3.08 a 3.16

Violines Oboe Fagot

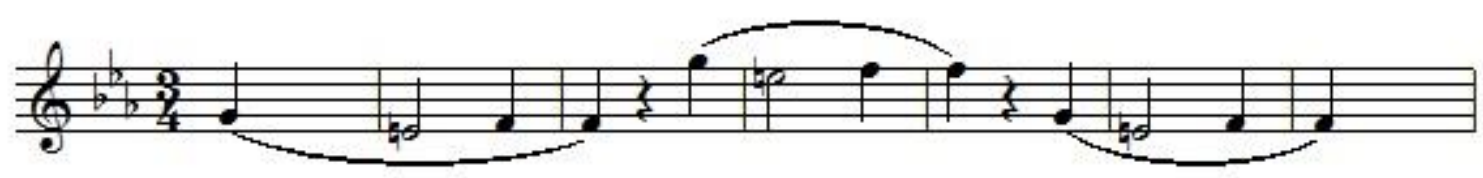




\section{Tema D 1.}

- Original - Beethoven. $5^{\text {ta }}$ Sinfonía $1^{\text {er }}$ movimiento

Tímbrica: Alternancia cuerdas y maderas

Métrica: Compás 461 a 469

Minutaje de la filmación: 5.08 a 5.13

Cuerdas tutti Vientos tutti

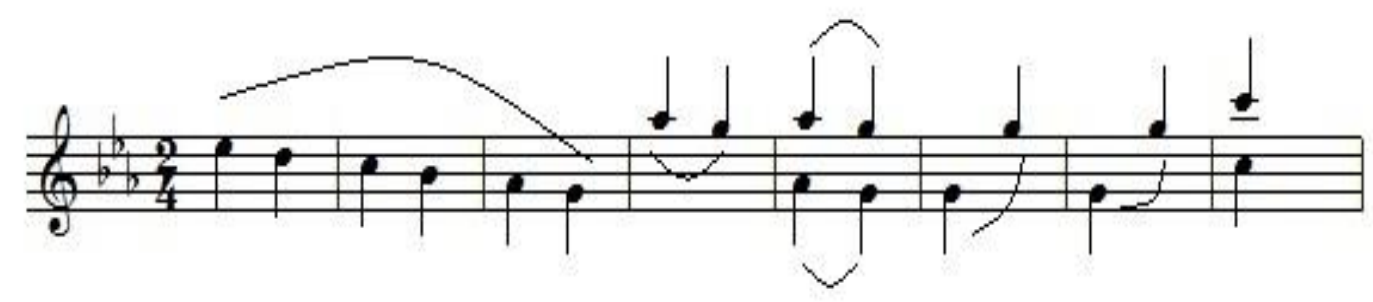

Texto: Ya te he dicho basta Basta Basta No No No No No

Congruencia entre rítmica, concertación y carácter (música/gesto)

\section{Tema D 2.}

- Distractor-Beethoven. $3^{\text {ra }}$ Sinfonía $3^{\text {er }}$ movimiento

Tímbrica: Alternancia entre cuerdas, maderas y tutti

Métrica: Compás 154 a 160

Minutaje de la versión audio: 2.27 a 2.30

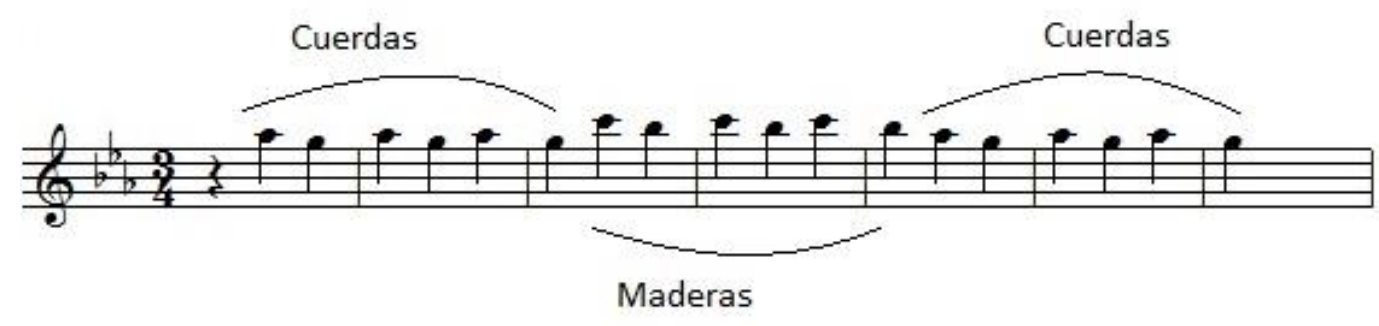




\section{II.- 7 Aplicación del Test. Interacción tesista alumnos.}

\section{II-7 a. GUIÓN para el GRUPO CONTROL:}

1- Vamos a escuchar una obra musical: la $5^{\text {ta }}$ sinfonía de Ludwing van Beethoven, un compositor del siglo XVIII. Vamos a escuchar el primer movimiento (Escuchan el primer movimiento completo)

2- Escuchen un fragmento de este movimiento. El instrumento que lo interpreta es uno de la Familia de los Vientos de metal. Se llama CORNO El corno es un instrumento de viento que frecuentemente se utiliza como toque de alerta o en las películas de guerra- (Escuchan el fragmento A1)

3- Vamos a escuchar, otro fragmento musical. Este lo hace OTRO INSTRUMENTO Ilamado OBOE. Es un instrumento de la Familia de los vientos de madera y se asocia, muchas veces, a escenas amorosas. (Escuchan el fragmento B1)

4- El siguiente fragmento es una melodía que se repite. La primera vez que se escucha lo presentan instrumentos de la familia de las cuerdas. Son los violines, las violas y los violoncellos. Cuando se repite la melodía la hace el CLARINETE que es un instrumento de viento de madera. (Escuchan el fragmento C1).

5- En el próximo fragmento vamos a escuchar cómo se alternan y superponen LAS MELODÍAS, como si hubiera un juego entre los instrumentos de cuerda y viento. (Escuchan el fragmento D1).

6- Ahora volveremos a escuchar todo el primer movimiento nuevamente. Traten de reconocer los fragmentos que analizamos anteriormente. Yo voy a ayudarlos. 


\section{Orden de aparición de los fragmentos}

1: corno.

2 repetición cuerdas /clarinete

3- oboe

4.- alternancia y superposición cuerdas / vientos

\section{II-7 b. GUIÓN para el GRUPO EXPERIMENTAL}

1- Los invito a ver un VIDEO. Se llama Argumento para la $5^{\text {ta }}$ Sinfonía de Beethoven. Ludwing van Beethoven, un compositor del siglo XVIII (Observan el video completo)

2- Ahora vamos a ver un fragmento del video. Es como si el actor dijera junto con la melodía "vamos a ver, a ver". Digámoslo juntos...Repítanlo conmigo, vamos....

El ritmo y la melodía de este fragmento lo hace un instrumento que se llama CORNO. Es un instrumento de la Orquesta sinfónica que pertenece a la Familia de los Vientos de metal. Generalmente se utiliza como toque de alerta o en las películas de guerra. (Observan el fragmento A1). 
3- En el próximo fragmento que vamos a ver pareciera que la actriz dijera junto con la melodía "Estoy sufriendo mucho".

Aquí aparece un instrumento de la familia de vientos de madera llamado $\mathrm{OBOE}$, que es un instrumento que se utiliza generalmente asociado a escenas amorosas. (Miran el fragmento B1).

4- -En el siguiente fragmento aparece una melodía que se repite igual. Pareciera que el actor dice con la melodía "Yo seré muy razonable". Y la actriz le responde también "Yo seré muy razonable".

Ambas melodías (iguales que se repiten) están presentadas por distintos instrumentos. Al "hablar" el actor lo hace con las cuerdas: violines, violas y cellos. Lo que "habla" la actriz, por el CLARINETE, que es un instrumento de viento de madera. (Observan el fragmento C1).

5- En este fragmento, los actores hablan a la vez y es como si dijeran al ritmo de la melodía "Ya (mi) tehe (re) di (do)cho (si) bas (la) ta (sol), bas (la) ta, (sol) bas(la) ta (sol)no(sol) no(sol), no(sol), no(sol), no (do)" Repitan conmigo a ver?.

Escuchamos cómo se alternan y superponen los instrumentos de cuerdas y los vientos.

(Observan el fragmento D1).

6- Ahora les propongo que veamos todo el video completo de nuevo. Tratemos de ir reconociendo los fragmentos que analizamos previamente. 
Cada vez que los reconozcamos diremos la frase que asociamos al texto. Yo los voy a ayudar.

Repasemos repitiendo cada fragmento

Orden de aparición de los fragmentos:

1- vamos a ver, a ver.

2- Yo seré muy razonable, yo seré muy razonable

3- Estoy sufriendo mucho

4- Ya te he dicho Basta Basta Basta Basta No No No No No

(Escuchan nuevamente la obra completa)

La tesista realizó ensayos informales con sus familiares y sus alumnos de la carrera especializada para ajustar detalles del test. Estos ensayos se realizaron, el primero, en el entorno familiar y, el segundo, en un aula de la Facultad de Artes y Diseño. Fue realizado con 9 alumnos que se distribuyeron en bancos separados.

Se propuso realizar el ensayo en el aula donde se desarrolla la jornada escolar diaria para la experiencia.

El grupo fue subdividido, al azar, en dos (uno a la manera de Grupo Control y el otro, experimental). Cada grupo contaba aproximadamente, con la misma cantidad de alumnos. Los alumnos se distribuyeron en hileras de bancos separados para evitar la observación de las respuestas de otros compañeros. Se les pidió que tuvieran a mano solamente un lápiz y una goma. Se les explicó que podían poner su nombre o un seudónimo en la hoja entregada. 
En cada grupo se explicó en qué consistían las actividades de audición y de observación, según lo que correspondiese al Grupo tomado como Control o el Grupo tomado como Experimental. Ajustados los detalles se administró la prueba piloto en la cual se escucharon y observaron cada uno de los fragmentos musicales seleccionados, según el grupo en el que estuvieran.

Una vez realizadas las actividades se distribuyó el cuadro de completamiento, aclarando que debían consignar la respuesta en el cuadrado correspondiente utilizando una cruz. A partir de la audición de las pruebas $W$ y $Z$, cada uno de los subgrupos realizó la prueba final.

La diferencia entre el test $\mathbf{W}$ y $\mathbf{Z}$ (pruebas finales) fue el orden de aparición de los fragmentos musicales, a saber: 


\section{TEST W:}

Tema A 2 .Distractor -Beethoven $3^{\text {ra }}$ Sinfonía $2^{\text {do }}$ Movimiento

Tema D 2 .Distractor -Beethoven. $3^{\text {ra }}$ Sinfonía $3^{\text {er }}$ movimiento

Tema C 1 .Original - Beethoven. $5^{\text {ta }}$ Sinfonía $1^{\mathrm{er}}$ movimiento

Tema B 1 .Original - $5^{\text {ta }}$ Sinfonía $1^{\text {er }}$ movimiento

Tema C 2 .Distractor -Beethoven. $3^{\text {ra }}$ Sinfonía $1^{\text {er }}$ movimiento

Tema A 1 .Original - $5^{\text {ta }}$ Sinfonía $1^{\text {er }}$ movimiento

$\underline{\text { Tema D }} 1$.Original - Beethoven. $5^{\text {ta }}$ Sinfonía $1^{\text {er }}$ movimiento

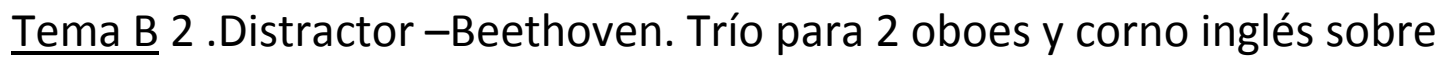
un tema de "Don Juan" de Mozart.

\section{TEST Z:}

Tema D 2. Distractor -Beethoven. $3^{\text {ra }}$ Sinfonía $3^{\text {er }}$ movimiento

Tema C 1 . Original - Beethoven. $5^{\text {ta }}$ Sinfonía $1^{\mathrm{er}}$ movimiento

$\underline{\text { Tema D }} 1$. Original - Beethoven. $5^{\text {ta }}$ Sinfonía $1^{\mathrm{er}}$ movimiento

Tema B 2. Distractor -Beethoven. Trío para 2 oboes y corno inglés sobre un tema de "Don Juan" de Mozart.

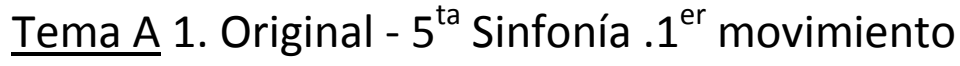

Tema B 1 . Original - $5^{\text {ta }}$ Sinfonía $.1^{\text {er }}$ movimiento

Tema C 2. Distractor -Beethoven. $3^{\text {ra }}$ Sinfonía $1^{\text {er }}$ movimiento

Tema A 2 .Distractor -Beethoven $3^{\text {ra }}$ Sinfonía $2^{\text {do }}$ Movimiento

\section{Institución:}

Instituto "Nuestra Señora de Rosario de Pompeya" PT -068.

Estudiantes participantes del grupo control:

Grupo de alumnos de 1 año de Ciencias Sociales y Humanidades " $A$ ". 
Estudiantes participantes del grupo experimental:

Grupo de alumnos de 1 año de Ciencias Sociales y Humanidades "B".

Equipamiento para la prueba piloto:

Cañón: HITACHI Multimedia LSD Projector CP-RS55

Reproductor de sonido PHILIPS-CD Soundmachine A2 1839 


\section{CAPÍTULO III}

\section{RESULTADOS (ver anexo)}




\section{III.1 Administración y resultados de la Prueba piloto}

Se tomó en cuenta el 1 para los aciertos y el 0 para los desaciertos.

Los resultados obtenidos fueron los siguientes:

\section{Grupo Control:}

\begin{tabular}{|c|c|c|c|c|c|c|c|c|}
\hline \multirow{2}{*}{ SEXO } & \multicolumn{8}{|c|}{ FRAGMENTOS } \\
\hline & 1 & 2 & 3 & 4 & 5 & 6 & 7 & 8 \\
\hline $\mathbf{F}$ & 1 & 1 & 1 & 1 & 0 & 1 & 1 & 1 \\
\hline $\mathbf{F}$ & 0 & 0 & 1 & 1 & 1 & 1 & 1 & 1 \\
\hline $\mathbf{F}$ & 1 & 1 & 1 & 0 & 0 & 1 & 1 & 0 \\
\hline M & 1 & 1 & 1 & 1 & 1 & 1 & 1 & 0 \\
\hline $\mathbf{F}$ & 1 & 0 & 1 & 1 & 1 & 1 & 0 & 1 \\
\hline $\mathbf{F}$ & 1 & 1 & 1 & 1 & 1 & 1 & 1 & 1 \\
\hline $\mathbf{F}$ & 1 & 1 & 1 & 1 & 1 & 1 & 0 & 1 \\
\hline M & 1 & 0 & 1 & 0 & 0 & 1 & 1 & 1 \\
\hline $\mathbf{F}$ & 1 & 1 & 1 & 0 & 0 & 1 & 1 & 1 \\
\hline $\mathbf{F}$ & 0 & 0 & 1 & 1 & 1 & 1 & 1 & 1 \\
\hline $\mathbf{F}$ & 1 & 0 & 0 & 1 & 1 & 1 & 0 & 1 \\
\hline \multirow[t]{2}{*}{$\mathbf{F}$} & 1 & 0 & 1 & 1 & 1 & 0 & 1 & 1 \\
\hline & 10 & 6 & 11 & 9 & 8 & 11 & 9 & 10 \\
\hline \multicolumn{8}{|l|}{ Total aciertos } & 74 \\
\hline \multicolumn{8}{|l|}{ Alumnos } & 12 \\
\hline
\end{tabular}


Grupo Experimental:

\begin{tabular}{|c|c|c|c|c|c|c|c|c|}
\hline \multirow{2}{*}{ SEXO } & \multicolumn{8}{|c|}{ FRAGMENTOS } \\
\hline & 1 & 2 & 3 & 4 & 5 & 6 & 7 & 8 \\
\hline$M$ & 1 & 1 & 1 & 0 & 1 & 1 & 1 & 1 \\
\hline $\mathbf{F}$ & 1 & 1 & 1 & 1 & 1 & 1 & 1 & 1 \\
\hline $\mathbf{F}$ & 0 & 1 & 1 & 0 & 1 & 1 & 1 & 1 \\
\hline M & 1 & 1 & 1 & 1 & 1 & 1 & 1 & 1 \\
\hline $\mathbf{F}$ & 1 & 1 & 1 & 1 & 1 & 1 & 1 & 1 \\
\hline $\mathbf{F}$ & 1 & 1 & 1 & 0 & 1 & 0 & 1 & 1 \\
\hline $\mathbf{F}$ & 1 & 1 & 1 & 1 & 0 & 1 & 1 & 0 \\
\hline $\mathbf{F}$ & 1 & 1 & 1 & 1 & 1 & 0 & 1 & 1 \\
\hline $\mathbf{F}$ & 1 & 1 & 1 & 1 & 1 & 0 & 1 & 1 \\
\hline $\mathbf{F}$ & 0 & 1 & 1 & 0 & 1 & 0 & 1 & 1 \\
\hline M & 1 & 1 & 1 & 1 & 1 & 1 & 1 & 1 \\
\hline M & 1 & 1 & 1 & 1 & 1 & 0 & 0 & 0 \\
\hline \multirow[t]{2}{*}{$\mathbf{F}$} & 0 & 1 & 1 & 1 & 1 & 1 & 0 & 1 \\
\hline & 10 & 13 & 13 & 9 & 12 & 8 & 11 & 11 \\
\hline \multicolumn{8}{|l|}{ Total aciertos } & 86 \\
\hline \multicolumn{8}{|l|}{ Alumnos } & 13 \\
\hline
\end{tabular}

Los resultados obtenidos en la prueba piloto generaron las siguientes preguntas:

1.- Si el grupo sometido a la prueba es un grupo de escuela secundaria, ¿por qué hubo resultados similares a los obtenidos por un grupo de alumnos estudiantes de Música?

2.- ¿Por qué se parecen tanto los resultados de los Grupos Control y Experimental?

3.- ¿Cómo fueron divididos?

4.- ¿Cuánto de ayuda tuvieron los sujetos del grupo control?

5.- ¿La tesista fue prescindente y no colaboradora?

6.- ¿Cómo fue el recreo/reemplazo de los grupos? 
7.- ¿Pudieron intercambiar opiniones entre quienes habían cumplimentado el test y quienes no lo habían realizado aún?

8.- ¿Se respondieron preguntas de los alumnos?

9.- ¿Se repitió algún ejemplo musical en la prueba?

\section{III-2 Conclusiones de la prueba piloto}

- La prueba se aplicó en el mismo espacio físico al de todos los días (aula donde cursan la jornada escolar).

- Solamente estuvo la investigadora con los alumnos lo que dificultó la dinámica de entrada y salida de los grupos.

- Se explicaron excesivamente y, fuera del protocolo, algunos elementos básicos de las audiciones.

- Ante la insistencia de los estudiantes, se repitieron algunos ejemplos auditivos no previstos en el protocolo.

- La tesista no fue imparcial en su expresividad al sugerir y guiar a los estudiantes en la primera prueba.

- Se respondieron preguntas de los alumnos.

- El recreo fue de más de 5’.

- El recambio de un grupo por otro permitió diálogos entre los alumnos. 


\section{III-3- Ajustes del experimento post prueba piloto}

A partir de la prueba piloto se tomaron algunas medidas para garantizar la aplicación objetiva de la prueba experimental (final)

$\checkmark$ Se destinó más tiempo para la prueba (40'). El tiempo de ésta fue un poco mayor y se solicitó, a los profesores correspondientes, el uso del tiempo necesario hasta la finalización de la prueba.

$\checkmark$ Se utilizó un espacio físico más grande en el subsuelo de la institución.

$\checkmark$ No se repitieron fragmentos auditivos a pedido.

$\checkmark$ No se respondieron preguntas de los alumnos.

$\checkmark$ La experiencia fue realizada con la colaboración de una preceptora que ayudó en la organización de la entrada y salida de los grupos de alumnos.

\section{III-4- Prueba final}

La variable "aciertos" (que resulta de la sumatoria de los aciertos de los 8 fragmentos) es cuantitativa de distribución normal (ver Gráfico PP-gráfico 8). Responde a los aciertos que tuvieron los alumnos de 2 colegios frente a 2 tipos de estímulos: Control (auditivo) y Experimental (visual y auditivo)

El tamaño de la muestra es de 60 casos y el nivel de significancia es de 5\%.

Gráfico 1

\begin{tabular}{|c|c|c|c|c|c|c|c|c|c|}
\hline & & \multicolumn{7}{|c|}{ ACIERTOS } & \multirow{2}{*}{ Total } \\
\hline & & 2 & 3 & 4 & 5 & 6 & 7 & 8 & \\
\hline \multirow{2}{*}{ Estimulo } & Control (auditivo) & 2 & 5 & 8 & 4 & 6 & 4 & 1 & 30 \\
\hline & Experimental (visual y auditivo) & 0 & 0 & 1 & 2 & 6 & 12 & 9 & 30 \\
\hline & Total & 2 & 5 & 9 & 6 & 12 & 16 & 10 & 60 \\
\hline
\end{tabular}




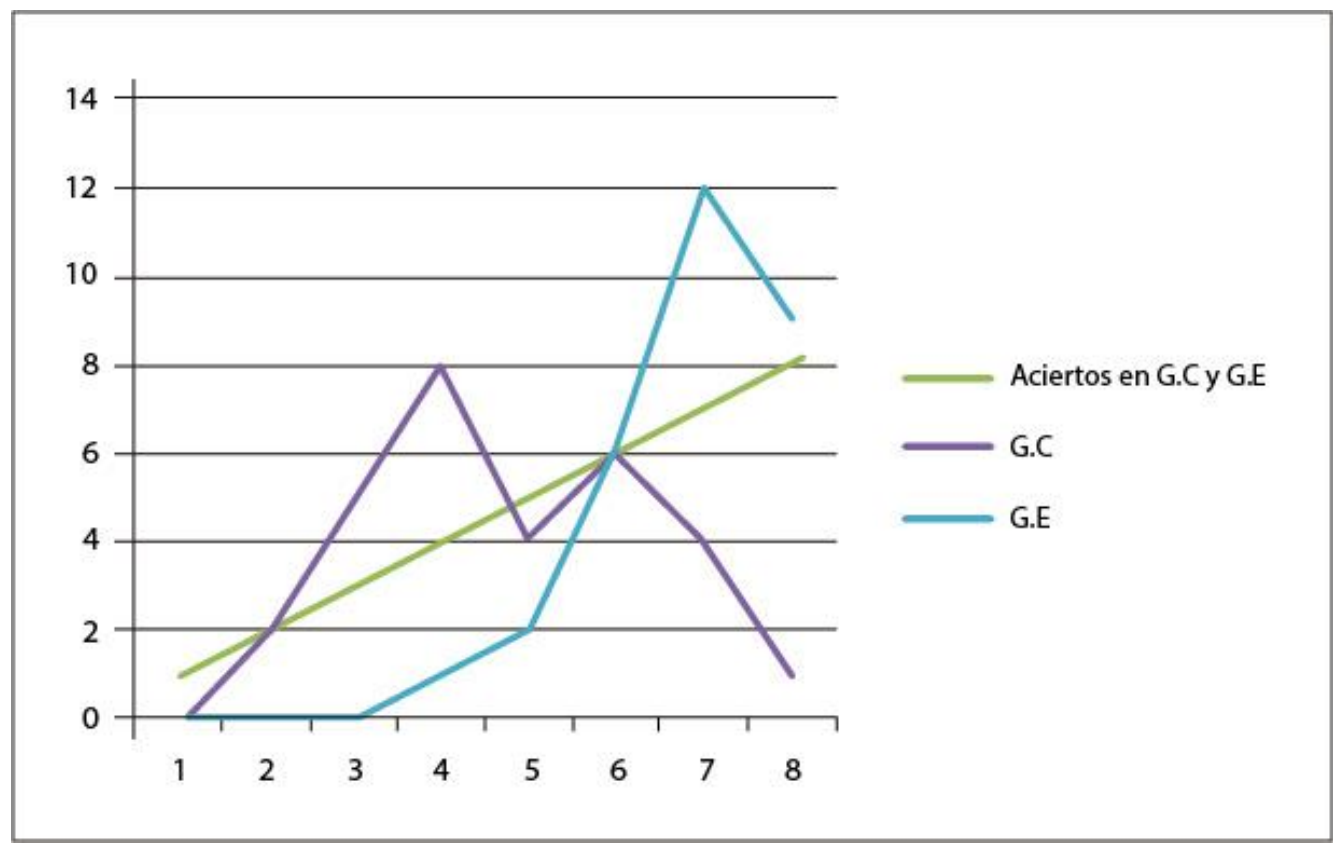

Gráfico 2

El gráfico 2 muestra la diferencia de aciertos entre el grupo control y el experimental con el puntaje más alto de 4 aciertos por 8 alumnos en el GC y un máximo de 7 aciertos por 12 alumnos en el GE.

Esto significa que

- en el Grupo Control el mayor acierto es en el $50 \%$ de los ejemplos, al que accedieron un máximo de 4 alumnos o sea un $13 \%$ del grupo en cambio

- en el GE el mayor acierto es en $88 \%$ de los ejemplos al que accedieron 12 alumnos o sea un $40 \%$ de los alumnos del grupo.

\begin{tabular}{|c|c|c|c|c|c|c|c|c|c|}
\hline & \multicolumn{7}{|c|}{ ACIERTOS } & \multirow{2}{*}{ Total } \\
\cline { 2 - 10 } & & 2 & 3 & 4 & 5 & 6 & 7 & 8 & \\
\multirow{2}{*}{ TEST } & $\mathbf{W}$ & 1 & 3 & 4 & 3 & 5 & 11 & 3 & 30 \\
\cline { 2 - 11 } & $\mathbf{Z}$ & 1 & 2 & 5 & 3 & 7 & 5 & 7 & 30 \\
\hline \multicolumn{2}{|c|}{ Total } & 2 & 5 & 9 & 6 & 12 & 16 & 10 & 60 \\
\hline
\end{tabular}

Gráfico 3 


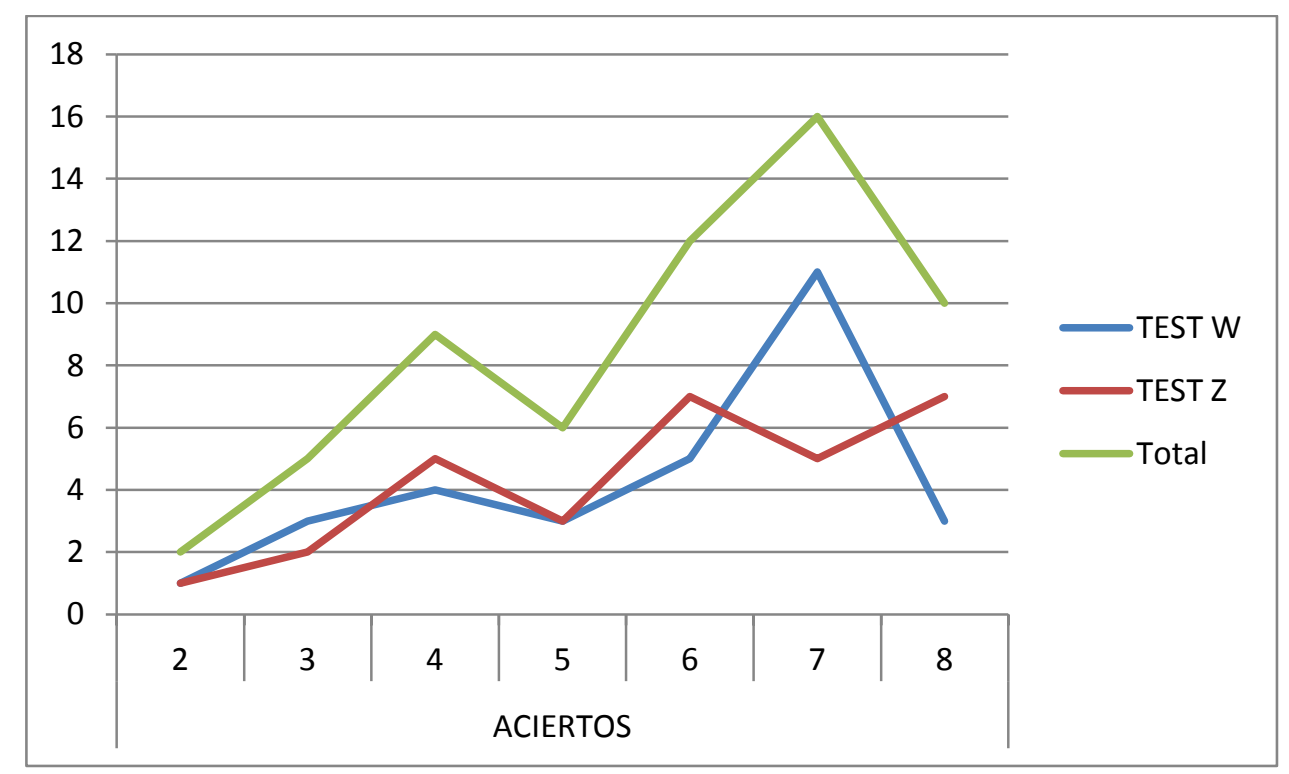

Gráfico 4

El gráfico 4 muestra las diferencias entre el test versión $W$ y el test $Z$

- se observa un pico en la curva del test $Z$ entre los 6 y 8 aciertos. La tabla da cuenta de que esos aciertos fueron de 14 alumnos, esto es del $47 \%$ de los alumnos

- el pico en el test $W$ se produce entre los 6 y 7 aciertos La tabla informa que 16 alumnos los obtuvieron. Esto es un $54 \%$ de los alumnos

\section{Diferencias entre Grupo1 y Grupo 2}

\begin{tabular}{|c|c|c|c|c|c|c|c|c|c|}
\hline & \multicolumn{7}{c|}{ ACIERTOS } & \multirow{2}{*}{ Total } \\
\cline { 2 - 10 } & & 2 & 3 & 4 & 5 & 6 & 7 & 8 & \\
\hline \multirow{2}{*}{ GRUPO } & 1 & 1 & 3 & 7 & 3 & 5 & 8 & 2 & 29 \\
\hline
\end{tabular}

Gráfico 5 


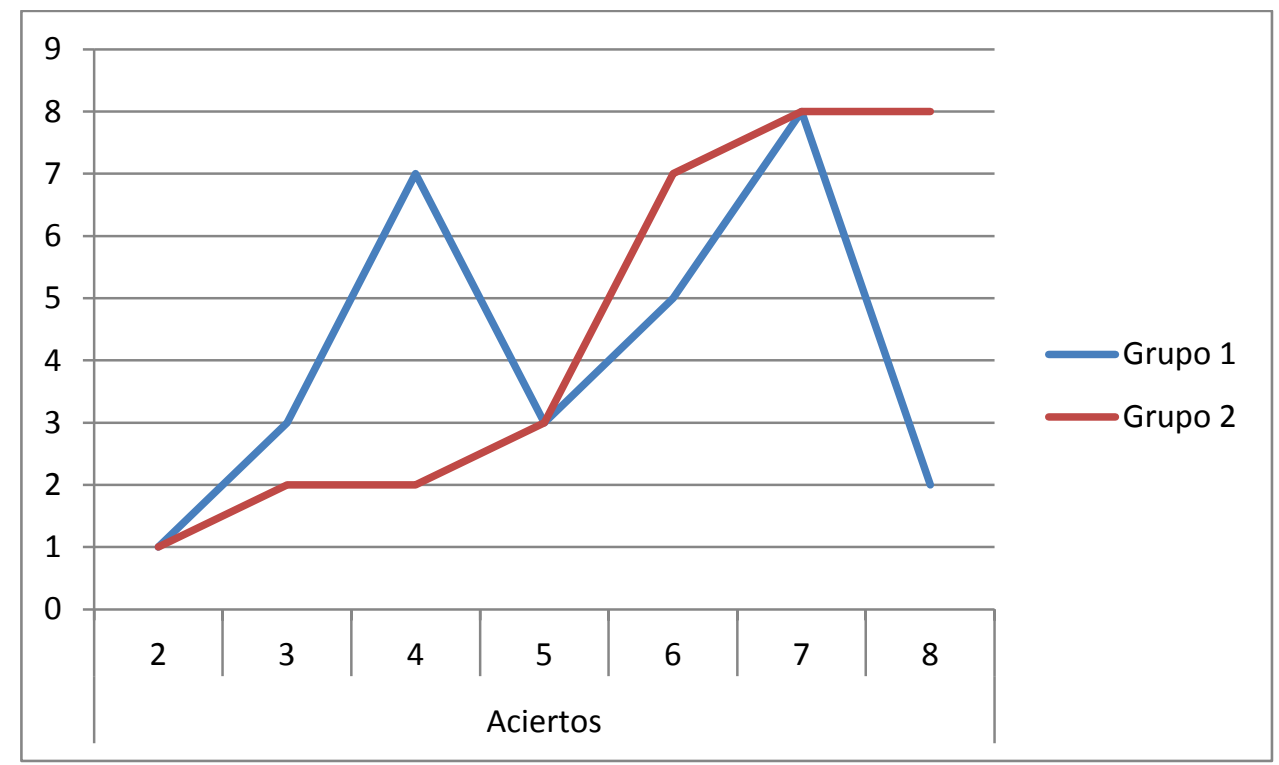

Gráfico 6

Los gráficos 5 y 6 muestran que:

- el grupo 1 muestra cierta dispersión en la distribución del número de aciertos

- el grupo 2 es más estable en la distribución del número de aciertos

Se realiza la prueba estadística "Anova de un factor".

La prueba es bilateral y se desea saber si el promedio de los aciertos difiere entre los tipos de estímulo.

Aciertos es la variable cuantitativa y por otro lado, el factor de agrupación es la variable dicotómica y cualitativa "estímulo" Control (auditivo) y Experimental (visual y auditivo) 
Anova de un factor

\begin{tabular}{|c|c|c|c|c|c|c|c|c|}
\hline \multicolumn{9}{|c|}{ ACIERTOS } \\
\hline & \multirow{2}{*}{$\mathbf{N}$} & \multirow{2}{*}{ Media } & \multirow{2}{*}{$\begin{array}{l}\text { Desviación } \\
\text { típica }\end{array}$} & \multirow{2}{*}{$\begin{array}{l}\text { Error } \\
\text { típico }\end{array}$} & \multicolumn{2}{|c|}{$\begin{array}{c}\text { Intervalo de confianza para } \\
\text { la media al } 95 \%\end{array}$} & \multirow{2}{*}{ Mínimo } & \multirow{2}{*}{ Máximo } \\
\hline & & & & & $\begin{array}{l}\text { Límite } \\
\text { inferior }\end{array}$ & $\begin{array}{l}\text { Límite } \\
\text { superior }\end{array}$ & & \\
\hline Control (auditivo) & 30 & 4,77 & 1,612 & 0,294 & 4,16 & 5,37 & 2 & 8 \\
\hline $\begin{array}{c}\text { Experimental (visual y } \\
\text { auditivo) }\end{array}$ & 30 & 6,87 & 1,042 & 0,190 & 6,48 & 7,26 & 4 & 8 \\
\hline Total & 60 & 5,82 & 1,712 & 0,221 & 5,37 & 6,26 & 2 & 8 \\
\hline
\end{tabular}

Gráfico 7

Los resultados del gráfico 6 en la prueba ANOVA muestran que:

- el Grupo Control obtiene una media considerablemente más alta que el Grupo Experimental.

- la desviación típica muestra una mayor estabilidad en el Grupo Experimental respecto del Grupo Control

Gráfico P-P Normal de ACIERTOS

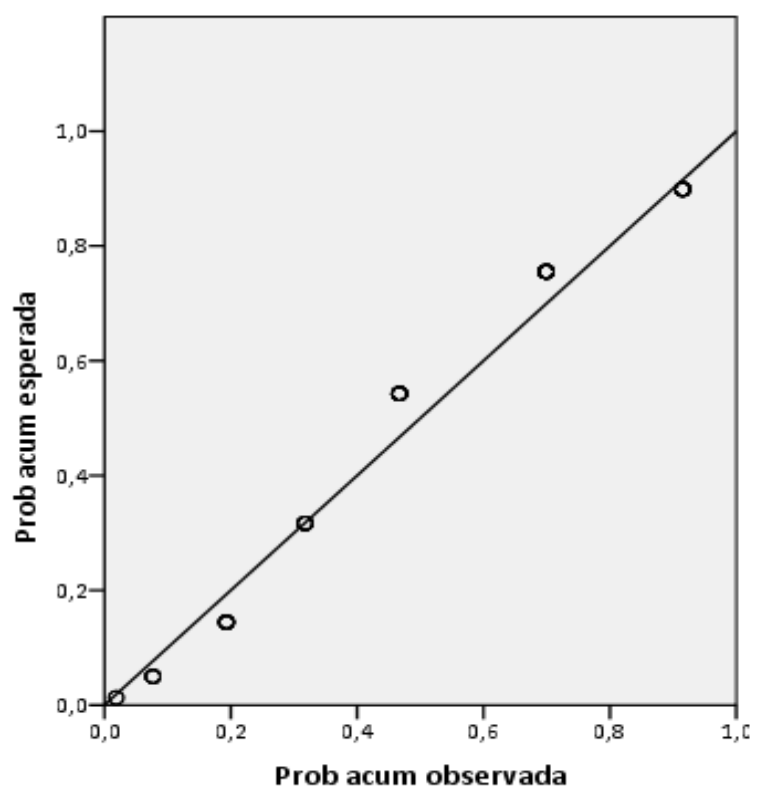

Gráfico 8 
- el límite superior no llega a los seis puntos en el GC y supera los 7 (sobre ocho) en el GE.

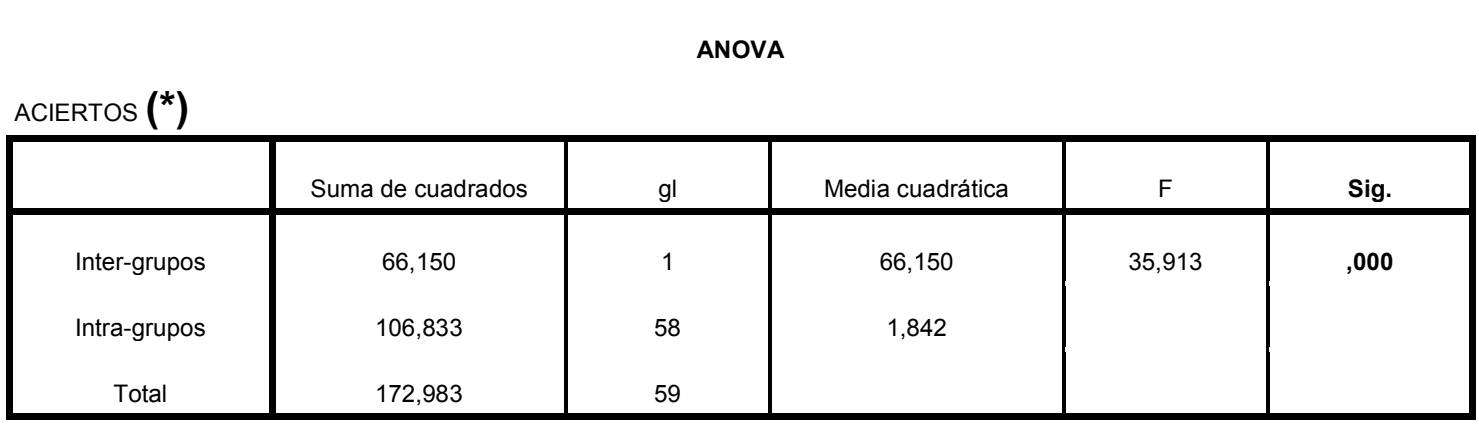

Gráfico 9

La significación estadística obtenida $\mathbf{0 , 0 0 0}$ muestra la potencia del test-

\section{Parámetros de distribución estimados}

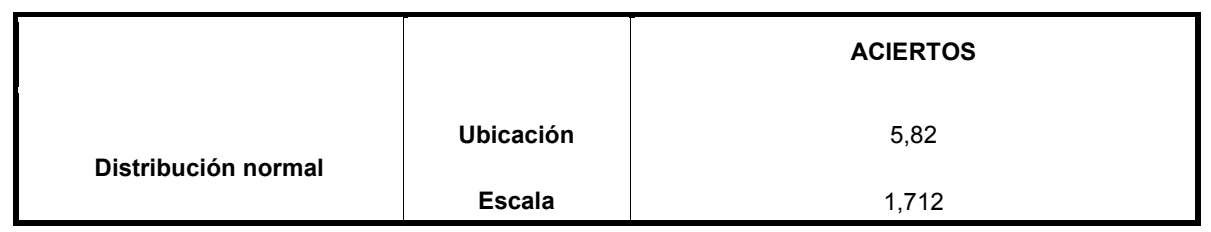

Gráfico 10

Los casos están sin ponderar. 


\section{CAPÍTULO IV}

CONCLUSIONES Y APORTES POTENCIALES 


\section{Conclusiones:}

El análisis estadístico de los diferencias entre el Grupo Control (GC) y el Grupo Experimental (GE), muestra que:

$\checkmark$ La media de aciertos es significativamente más alta en el grupo experimental.

Resultados que mostrarían que ante alumnos de igual o similar nivel de edad y condición socio-económica, la entrada de estímulos multimodales aumenta la comprensión, facilita la memorización/retención, e incrementa la significación del aprendizaje.

Los grupos control y experimental (estadísticamente iguales) fueron enfrentados con idéntico estímulo musical; la diferencia estribó en el refuerzo del tratamiento con estímulos multisensoriales agregados y la proyección del film.

Resultados que muestran el rol de la multisensorialidad en la percepción y comprensión de contenidos artísticos.

$\checkmark$ La variabilidad de los puntajes intra-grupo (desviación típica) es menor en el grupo experimental.

Resultado que asegura la estabilidad de las respuestas en el grupo con estimulación multimodal, como así también rechaza la presunción del acierto por azar.

Las descripciones verbales de los instrumentos musicales de la prueba fueron idénticas para ambos grupos. Las diferencias fueron las frases verbales elegidas y utilizadas solamente para el grupo experimental 
(target). Tales frases fueron creadas para el experimento, se basaron en el concepto de congruencia entre las sintaxis de ambos lenguajes.

Los alineamientos temporales:

i) número de ataques del ritmo musical versus número de sílabas del texto lingüístico;

ii) la distribución en el tiempo de los ataques y acentos del ritmo musical versus los acentos prosódicos del texto.

Los alineamientos emocionales basados en el encuentro entre el carácter de la música y el contenido emocional de las palabras.

La distribución de la muestra es normal y los puntajes obtenidos son producto de un grupo natural de la escuela media.

Resultados que confirman que el grupo de alumnos representa a la población de pertenencia y que podrían obtenerse puntajes similares en otras muestras de alumnos de la enseñanza media mendocina.

$\checkmark$ El test mide lo que se intenta medir.

Resultado que muestra que el recurso musical "per se", utilizado en el grupo control, no es suficiente para la comprensión de la obra. Las diferencias son el producto de la visualización del film con juego dramático basado en la obra musical y su sintaxis, así como los refuerzos visuales, verbales y auditivos utilizados en el tratamiento del GE.

$\checkmark$ Las diferencias en el estilo de tratamiento y administración de la prueba piloto respecto de la prueba experimental, signaron las diferencias entre ambas. 
Resultado que enseña acerca de las diferencias entre una prueba de naturaleza pedagógica y una prueba científica. Pueden señalarse como indicios:

i) responder a preguntas de los estudiantes, referidas al contenido del test.

ii) mostrar gestos de aprobación o rechazo ante preguntas de los estudiantes.

$\checkmark$ El lugar de administración del test y el modo de relevo entre grupos necesita un arreglo del entorno y la movilidad de los participantes.

Resultados que muestran la diferencia entre la prueba piloto (en que ambos recaudos no fueron tenidos en cuenta) y la experimental.

\section{Aportes Potenciales}

La psicología cognitiva aporta una mirada diferente a la pedagogía musical. A partir de los resultados obtenidos en este trabajo, en las aulas de música y en la formación del docente musical, se debería integrar recursos integrados multisensorialmente entre las imágenes y los estímulos sonoros presentados así como también juegos corporales que den cuenta de la congruencia entre los diferentes lenguajes.

En función del planteo y comprobación de la tesis en las diferentes etapas de implementación se generaron acciones de capacitación e investigación acción sobre nuevas metodologías para trabajar en el aula. Una de ellas fue la propuesta de un curso para docentes de Educación Musical y estudiantes avanzados de los Profesorados de Música de Educación Musical de diferentes niveles educativos de la provincia de Mendoza. El mismo se denominó 
"Experiencias Multisensoriales en el aula de Música". Fue dictado en el marco del Programa NUESTRA ESCUELA, programa nacional de formación permanente (PNFP, componente 2). El mismo se desarrolló con modalidad semi-presencial. Desde esta perspectiva en los fundamentos del proyecto se consideró que el curso "hace anclaje desde lo pedagógico y vocal en el modelo Cross-modal que propone partir del principio de que las experiencias multisensoriales incrementan la comprensión y placer del auditor-espectador".

El trabajo final se radicará en la biblioteca de la U.N.Cuyo, en las Carreras Musicales de la Facultad de Artes y Diseño de la Universidad Nacional de Cuyo como material de consulta y se ofrecerá a las instituciones de enseñanza secundaria de la provincia.

Se desarrollarán escritos ampliatorios para los docentes del medio escolar de la región, interesados en el tema. 


\section{CAPÍTULO V}

\section{BIBLIOGRAFÍA}




\section{REFERENCIAS}

Basso, G. (2009). Percepción auditiva. Bernal: Universidad Nacional de Quilmes.

Cádiz, R. y De la Cuadra, P. "Reflexiones 25-Estrategias de composición audiovisual en sinestesia, isomorfismo e inteligencia artificial". http://www7.uc.cl/musica/cita/Resonancias/25/Cadiz.pdfCádiz,R. F. “Un modelo de lógica difusa para la composición enfoques de los medios audiovisuales" Programa de Tecnología Musical de la Escuela de Música de la Universidad de Northwestern. Bajado 09/11/13.

Cádiz, R. y De La Cuadra, P. Centro de Investigación en Tecnologías de Audio Pontificia Universidad Católica de Chile

http://www7.uc.cl/musica/cita/Resonancias/25/Cadiz.pdf.Pág 25.

Campos, A. L. (2010). "Neuroeducación: uniendo las neurociencias y la educación en la búsqueda del desarrollo humano". Revista digital: La educación-OEA-Junio 2010, № 143. http://www.educoea.org/portal/La Educacion Digital/laeducacion 143/ articles/neuroeducacion.pdf. Consultado 21/11/13

Cano, N.; Fernández, O.; Ferreyra, S.;Garzuzi, V. ; Jase, C. y Semenzato, S. (2011). El sujeto del aprendizaje en la escuela secundaria. Versión corregida septiembre 2011 Dirección General de Educación PreUniversitaria-U.N.Cuyo.

Cohen, A. (2001). Music as source of emotion in film. En P. Juslin y J. Sloboda: Music and Emotion. Theory and Research. Oxford: UP.

Cohen, A. (2005) How Music Influences Film and Video: Approaches from Experimental Psychology. En Kendall, Roger A,. \& Savage, Roger W. H.,(eds.).Perspectives in Systematic Musicology. California: UP

De Nora, T. (2000/2006 ). Music in everyday life. Cambridge: University Press

Dowling, J. (1994). Melodic contour in hearing and remembering melodies. En R. Aiello y J. Sloboda (Eds.), Musical perceptions (pp.173-186).Oxford University Press. 
Fogelsanger, A. y Afanador, K. (2006). Parameters of Perception: Audition, and Twentieth Century Music and dance. Congress on Research in Dance. Tempe: Arizona.

Gainza, V.,(2002) "Didáctica de la música contemporánea en el aula", Pedagogía Musical. Dos décadas de pensamiento y acción educativa. Buenos Aires: Editorial Lumen.

Gainza, V.(2003). La educación musical entre dos siglos: del modelo metodológico a los nuevos paradigmas. Bs As: GUADALUPE.

Guillén, J. C. (2012, diciembre). Neuroeducación: estrategias basadas en el funcionamiento del cerebro. http://escuelaconcerebro.wordpress.com/2012/12/27/neuroeducacionestrategias-basadas-en-el-funcionamiento-del-cerebro/. Bajado el $\underline{12 / 11 / 13}$

Hargreaves ,D, J, Mac Donald R y Miell, D. (2002). What are musical identities, and why are they important? In R, A.R. Mac Donald, D.J Hargreaves \& D.E. Miell(eds.). Musical Identities (pp 1-20).Oxford: Oxford University Press

Lerdahl, F. y Jackendoff, R. (1983/2003). Gramática Generativa de la Música Tonal. Madrid: AKAL.

Levitin, D., y Tirovolas, A. (2009). Current Advances in the Cognitive Neuroscience of Music. En The Year in Cognitive Neuroscience 2009 (pp.211-231). New York Academy of Sciences.

Lipscomb, S. (1999). Cross modal integration: Synchronization of auditory and visual components in simple and complex media. Journal of the Acoustical Society of America 105.Issue 2.

Lipscomb, S. (1995). Cognition of musical and visual accent structure alignment in film and animation. A doctoral dissertation submitted in partial satisfaction of the requirements for the degree Doctor of Philosophy in Music. University of California, Los Angeles 
Lipscomb, S. (1998). Cross-modal integration: Synchronization of auditory and visual components in simple and complex media. In Proceedings of de Conferences of the Acoustical Society of America, Norfolk VA.

Lipscomb, S. (1999). Cross modal integration: Synchronization of auditory and visual components in simple and complex media. Journal of the Acoustical Society of America 105. Issue 2.

Malbrán, M. del C. (1992). Reflexiones en torno a los adolescentes. Guía de enseñanza: pp. 8. En S. Malbrán; S. Furnó, y S. Espinosa, S. Resonancias. Libro 1 Fuentes sonoras. Buenos Aires: RICORDI.

Malbrán, S. (2008). El cruce de modalidades perceptivas. Un estudio sobre música y actuación. Primer Congreso Internacional. Artes en cruce: Problemáticas teóricas actuales. Buenos Aires: Universidad de Buenos Aires.

Malbrán, S. (2010) El modelo cross modal aplicado a las Artes Temporales. Cap. 1 En M. Díaz y M.E. Riaño (eds.). Voz, cuerpo y acción. Un espacio para la música. Santander: PUbliCan-Ediciones

Malbrán, S. (2010a). Sonido y música en el arte de la imagen. Cap. 2. In M. Díaz \& M.E. Riaño (eds.) Voz, cuerpo y acción. Un espacio para la música. Santander: PUbliCan Ediciones.

Malbrán, S. (2010b). El modelo cross modal aplicado a las Artes Temporales. Cap. 1. In M. Díaz \& M.E. Riaño (eds.). Voz, cuerpo y acción. Un espacio para la música. Santander: PUbliCan Ediciones.

Malbrán, S. (2002). Aportaciones de la Psicología cognitiva de la Música a la Educación Musical de hoy. Revista Aula 112.

Malbrán, S. y Menéndez, J. (2009). Integración cross modal y música. Encuentro Latinoamericano ISME. Buenos Aires

CFE. Resol. N $N^{\circ}$ 120/10, Modalidad Artística Criterios generales para la construcción de la Secundaria de Arte (Orientada, Especializada y Técnico /Artística)

http://www.me.gov.ar/consejo/resoluciones/cf.resoluciones.html. Pág.9 
Morduchowicz, R. (2004) El Capital Cultural de los Jóvenes. Mexico Fondo de Cultura Económica 19/04. http://www.bnm.me.gov.ar/cgibin/wxis.exe/opac/?lsisScript=opac/opac.x is \&dbn=BINAM\&tb=aut\&src=link\&query=MORDUCHOWICZ,\%20ROXANA \&cantidad=\&formato=\&sala=1 Bajado el 09/11/13

Morin, E. (1999). Los siete saberes necesarios para la educación del futuro. UNESCO: Francia.

Rascovan, S. (2005). Orientación Vocacional. Una perspectiva crítica. Buenos Aires: Paidós.

Reybrouck, M. (2005). Body, mind and music: musical semantics between experiential cognition and cognitive economy. Transcultural Music Review. 9.

\section{BIBLIOGRAFÍA CONSULTADA}

Ausubel, D y Sullivan, E. (1983).Psicología del desarrollo. Bs As: PAIDOS.

Assinato, M. V. La comprensión de la macro estructura musical en relación al lenguaje narrativo. Actas de la VII Reunión SACCOM Universidad Nacional de La

Plata. http://www.fba.unlp.edu.ar/educacionauditiva/investigacion/59.assinna to.pdf .Bajado 29/11/13

Cohen, G. (1983). Psicología Cognitiva. Madrid, Alhambra. Título original de The Psychology of cognition. 1977. Londres, Academic Press.

Gardner, H.(1995). Inteligencias múltiples: la teoría en la práctica, Bs As: PAIDÓS.

Malbrán, S. (2011). Desafíos de la educación musical: disfrutar haciendo música. En: A., Giráldez y., Pimentel, Educación artística, cultura y ciudadanía. De la teoría a la práctica. Serie Educación Artística. Capítulo 6. OEI 
Malbrán, S. (2001). La Sincronía Rítmica como forma particular de la organización temporal (Tesis doctoral) Facultad de Humanidades y Ciencias de la Educación La Plata UNLP.

Meyer, L. (2001). Emoción y significado en la música. Madrid: Alianza.

CFE. Res 120/10. Modalidad Artística Criterios generales para la construcción de la Secundaria de Arte (Orientada, Especializada y Técnico - Artística) http://www.me.gov.ar/consejo/resoluciones/cf.resoluciones.html

http://es.wikiversity.org/wiki/Aprendizaje_adolescente. Bajado el 22/11/13

http://adolescenteomnilateral.blogspot.com.ar/2010/05/como-aprende-unadolescente.html.Bajado el 12/11/13

http://en.wikipedia.org/wiki/Sid_Caesar

http://www.youtube.com/watch?v=EEhF-7suDsM Actores Sid Caesar y Nanette http://en.wikipedia.org/wiki/Nanette_Fabray

CFE. Res 120/10, Modalidad Artística Criterios generales para la construcción de la Secundaria de Arte (Orientada, Especializada y Técnico - Artística) http://www.me.gov.ar/consejo/resoluciones/cf.resoluciones.html 
ANEXO 
GRUPO CONTROL 1

\section{TEST W}

\begin{tabular}{|c|c|c|c|c|c|c|c|c|}
\hline \multirow{2}{*}{ SEXO } & \multicolumn{8}{|c|}{ FRAGMENTOS } \\
\hline & 1 & 2 & 3 & 4 & 5 & 6 & 7 & 8 \\
\hline M & 1 & 0 & 1 & 1 & 1 & 1 & 1 & 1 \\
\hline $\mathbf{F}$ & 1 & 0 & 1 & 0 & 0 & 1 & 1 & 0 \\
\hline$M$ & 1 & 0 & 1 & 0 & 0 & 0 & 1 & 1 \\
\hline M & 1 & 1 & 0 & 0 & 1 & 0 & 1 & 1 \\
\hline $\mathbf{F}$ & 0 & 0 & 1 & 1 & 1 & 1 & 1 & 0 \\
\hline $\mathbf{F}$ & 1 & 0 & 0 & 0 & 1 & 0 & 0 & 0 \\
\hline $\mathbf{F}$ & 0 & 0 & 0 & 0 & 1 & 1 & 1 & 0 \\
\hline$M$ & 0 & 1 & 0 & 0 & 1 & 0 & 0 & 1 \\
\hline Total aciertos & & & & & & & & 33 \\
\hline Alumnos & & & & & & & & 8 \\
\hline
\end{tabular}

\section{GRUPO CONTROL 1}

\section{TEST Z}

\begin{tabular}{|c|c|c|c|c|c|c|c|c|}
\hline \multirow{2}{*}{ SEXO } & \multicolumn{8}{|c|}{ FRAGMENTOS } \\
\hline & 1 & 2 & 3 & 4 & 5 & 6 & 7 & 8 \\
\hline $\mathbf{F}$ & 1 & 1 & 1 & 1 & 1 & 0 & 1 & 1 \\
\hline $\mathbf{F}$ & 0 & 1 & o & 0 & 1 & 0 & 0 & 1 \\
\hline M & 1 & 1 & 1 & 0 & 1 & 0 & 0 & 0 \\
\hline $\mathbf{F}$ & 1 & 1 & 1 & 1 & 1 & 0 & 0 & 1 \\
\hline $\mathbf{F}$ & 0 & 1 & 0 & 0 & 0 & 0 & 1 & 1 \\
\hline M & 1 & 1 & 0 & 0 & 1 & 0 & 0 & 1 \\
\hline $\mathbf{F}$ & 1 & 1 & 1 & 0 & 0 & 0 & 1 & 0 \\
\hline $\mathbf{F}$ & 0 & 0 & 0 & 0 & 0 & 0 & 0 & 1 \\
\hline \multicolumn{8}{|l|}{ Total aciertos } & 32 \\
\hline \multicolumn{8}{|l|}{ Alumnos } & 8 \\
\hline
\end{tabular}


GRUPO CONTROL 2

\section{TEST W}

\begin{tabular}{|c|c|c|c|c|c|c|c|c|}
\hline \multirow{2}{*}{ SEXO } & \multicolumn{8}{|c|}{ FRAGMENTOS } \\
\hline & 1 & 2 & 3 & 4 & 5 & 6 & 7 & 8 \\
\hline M & 1 & 0 & 1 & 0 & 1 & 1 & 1 & 1 \\
\hline $\mathbf{F}$ & 1 & 1 & 1 & 1 & 1 & 0 & 1 & 1 \\
\hline $\mathbf{F}$ & 1 & 0 & 1 & 1 & 1 & 1 & 0 & 1 \\
\hline M & 0 & 0 & 1 & 0 & 1 & 0 & 0 & 1 \\
\hline $\mathbf{F}$ & 1 & 1 & 1 & 1 & 0 & 1 & 1 & 1 \\
\hline $\mathbf{F}$ & 0 & 0 & 1 & 0 & 1 & 0 & 1 & 1 \\
\hline M & 1 & 0 & 1 & 0 & 0 & 0 & 1 & 1 \\
\hline \multicolumn{8}{|l|}{ Total aciertos } & 37 \\
\hline Alumnos & & & & & & & & 7 \\
\hline
\end{tabular}

\section{GRUPO CONTROL 2}

\section{TEST Z}

\begin{tabular}{|c|c|c|c|c|c|c|c|c|}
\hline \multirow{2}{*}{ SEXO } & \multicolumn{8}{|c|}{ FRAGMENTOS } \\
\hline & 1 & 2 & 3 & 4 & 5 & 6 & 7 & 8 \\
\hline$M$ & 0 & 1 & 1 & 1 & 0 & 1 & 1 & 1 \\
\hline $\mathbf{F}$ & 0 & 1 & 1 & 0 & 0 & 0 & 0 & 1 \\
\hline M & 1 & 1 & 1 & 1 & 1 & 1 & 1 & 1 \\
\hline M & 0 & 1 & 1 & 0 & 0 & 0 & 0 & 0 \\
\hline $\mathbf{F}$ & 0 & 1 & 1 & 1 & 1 & 0 & 1 & 1 \\
\hline M & 1 & 1 & 1 & 1 & 0 & 0 & 1 & 0 \\
\hline M & 1 & 1 & 1 & 0 & 1 & 0 & 1 & 1 \\
\hline $\mathbf{F}$ & 0 & 1 & 0 & 1 & 1 & 1 & 0 & 1 \\
\hline Total aciertos & & & & & & & & 40 \\
\hline Alumnos & & & & & & & & 8 \\
\hline
\end{tabular}


GRUPO EXPERIMENTAL 1 -

\section{TEST W}

\begin{tabular}{|c|c|c|c|c|c|c|c|c|}
\hline \multirow{2}{*}{ SEXO } & \multicolumn{8}{|c|}{ FRAGMENTOS } \\
\hline & 1 & 2 & 3 & 4 & 5 & 6 & 7 & 8 \\
\hline $\mathbf{F}$ & 1 & 1 & 1 & 1 & 1 & 1 & 1 & 1 \\
\hline $\mathbf{F}$ & 1 & 1 & 1 & 1 & 1 & 1 & 0 & 1 \\
\hline $\mathbf{F}$ & 1 & 1 & 1 & 1 & 0 & 1 & 1 & 1 \\
\hline $\mathbf{F}$ & 1 & 1 & 1 & 0 & 0 & 1 & 1 & 1 \\
\hline M & 1 & 1 & 1 & 1 & 0 & 1 & 1 & 1 \\
\hline $\mathbf{F}$ & 1 & 1 & 1 & 0 & 1 & 1 & 1 & 1 \\
\hline $\mathbf{F}$ & 1 & 1 & 1 & 0 & 0 & 1 & 1 & 1 \\
\hline \multicolumn{8}{|l|}{ Total aciertos } & 48 \\
\hline Alumnos & & & & & & & & 7 \\
\hline
\end{tabular}

\section{GRUPO EXPERIMENTAL 1}

\section{TEST Z}

\begin{tabular}{|c|c|c|c|c|c|c|c|c|}
\hline \multirow{2}{*}{ SEXO } & \multicolumn{8}{|c|}{ FRAGMENTOS } \\
\hline & 1 & 2 & 3 & 4 & 5 & 6 & 7 & 8 \\
\hline $\mathbf{F}$ & 1 & 1 & 1 & 1 & 1 & 1 & 0 & 1 \\
\hline $\mathbf{F}$ & 0 & 1 & 0 & 1 & 1 & 0 & 0 & 1 \\
\hline $\mathbf{F}$ & 1 & 1 & 1 & 1 & 1 & 0 & 1 & 1 \\
\hline M & 1 & 0 & 1 & 1 & 0 & 0 & 1 & 1 \\
\hline $\mathbf{F}$ & 1 & 1 & 1 & 1 & 0 & 0 & 1 & 1 \\
\hline $\mathbf{F}$ & 0 & 1 & 1 & 1 & 1 & 0 & 1 & 1 \\
\hline$M$ & 1 & 1 & 1 & 1 & 1 & 1 & 1 & 1 \\
\hline Total aciertos & & & & & & & & 42 \\
\hline Alumnos & & & & & & & & 7 \\
\hline
\end{tabular}


GRUPO EXPERIMENTAL 2

\section{TEST W}

\begin{tabular}{|c|c|c|c|c|c|c|c|c|}
\hline \multirow{2}{*}{ SEXO } & \multicolumn{8}{|c|}{ FRAGMENTOS } \\
\hline & 1 & 2 & 3 & 4 & 5 & 6 & 7 & 8 \\
\hline $\mathbf{F}$ & 1 & 1 & 1 & 1 & 1 & 1 & 1 & 1 \\
\hline M & 1 & 0 & 0 & 1 & 0 & 1 & 1 & 1 \\
\hline M & 1 & 0 & 1 & 0 & 1 & 1 & 1 & 1 \\
\hline $\mathbf{F}$ & 1 & 1 & 1 & 1 & 0 & 1 & 1 & 1 \\
\hline $\mathbf{F}$ & 1 & 0 & 1 & 1 & 1 & 1 & 1 & 1 \\
\hline $\mathbf{F}$ & 1 & 1 & 1 & 0 & 1 & 1 & 1 & 1 \\
\hline $\mathbf{F}$ & 1 & 1 & 1 & 0 & 1 & 1 & 1 & 1 \\
\hline $\mathbf{F}$ & 1 & 1 & 1 & 1 & 1 & 1 & 1 & 1 \\
\hline Total aciertos & & & & & & & & 55 \\
\hline Alumnos & & & & & & & & 8 \\
\hline
\end{tabular}

\section{GRUPO EXPERIMENTAL 2}

\section{TEST Z}

\begin{tabular}{|c|c|c|c|c|c|c|c|c|}
\hline \multirow{2}{*}{ SEXO } & \multicolumn{8}{|c|}{ FRAGMENTOS } \\
\hline & 1 & 2 & 3 & 4 & 5 & 6 & 7 & 8 \\
\hline$M$ & 1 & 1 & 1 & 1 & 1 & 1 & 1 & 1 \\
\hline $\mathbf{F}$ & 0 & 1 & 1 & 1 & 1 & 0 & 1 & 1 \\
\hline $\mathbf{F}$ & 1 & 1 & 1 & 1 & 1 & 1 & 1 & 1 \\
\hline $\mathbf{F}$ & 1 & 1 & 1 & 1 & 1 & 1 & 1 & 1 \\
\hline M & 1 & 1 & 0 & 1 & 1 & 1 & 1 & 1 \\
\hline $\mathbf{F}$ & 1 & 1 & 1 & 1 & 1 & 0 & 1 & 1 \\
\hline $\mathbf{F}$ & 1 & 1 & 1 & 1 & 1 & 1 & 1 & 1 \\
\hline M & 1 & 1 & 1 & 1 & 1 & 1 & 1 & 1 \\
\hline \multicolumn{8}{|l|}{ Total aciertos } & 60 \\
\hline \multicolumn{8}{|l|}{ Alumnos } & 8 \\
\hline
\end{tabular}

Los ejemplos en formato audio y audio video se encuentran en formato MP3. 
Percepción musical en formato audio y audiovisual. 
Percepción musical en formato audio y audiovisual. 